\title{
ИССЛЕДОВАТЕЛЬСКАЯ ДЕЯТЕЛЬНОСТЬ ШКОЛЬНИКОВ КАК СПОСОБ ФОРМИРОВАНИЯ ФУНКЦИОНАЛЬНОЙ ГРАМОТНОСТИ
}

\author{
Т.В. Корнилова \\ Московский гуманитарный университет
}

\begin{abstract}
Аннотация: Современный школьник должен быть ориентирован на развитие компетентностей, способствующих реализащии кониепщии «образование через всю жизнь». Это актуализирует проблему формирования функциональной грамотность обучающихся в различных видах их деятельности, включая исследовательскую.

Ключевые слова: исследовательская деятельность, функииональная грамотность, исследовательские умения, учебный процесс, внеурочная деятельность
\end{abstract}

\section{RESEARCH ACTIVITY OF SCHOOL CHILDREN AS A WAY OF FORMING FUNCTIONAL LITERACY}

\author{
T.V. Kornilova \\ Moscow University for the Humanities
}

\begin{abstract}
The modern school student should be focused on the development of competencies that contribute to the implementation of the concept of "education through life». This actualizes the problem of forming functional literacy of students in various types of their activities, including research.

Keywords: research activity, functional literacy, research skills, educational process, extracurricular activities
\end{abstract}

В современной России предъявляются высокие требования к подходам в обучении детей, направленным на повышение качества образования. Федеральный государственный образовательный стандарт основного общего образования ориентирован на становление личностных характеристик выпускника, который активно и заинтересованно познает мир, осознает ценность труда, науки и творчества, образования и самообразования, умеет учиться и способен применять полученные знания на практике.

Выпускник школы должен быть готов взаимодействовать с окружающим миром, решать учебные и жизненные задачи, выстраивать социальные отношения в соответствии с правилами сотрудничества, стремиться к образованию и самообразованию, к прогнозированию своего будущего. Следовательно, современная система образования ориентирована на развитие функциональной грамотности школьников.

Впервые термин «функциональная грамотность» был обозначен ЮНЕСКО в 1965 г., и определялся как международная проблема для развитых стран мира. Согласно А.А. Леонтьеву функциональная грамотность - это «способность человека использовать приобретаемые в течение жизни знания для решения широкого диапазона жизненных задач в различных сферах человеческой деятельности, общения и социальных отношений» (Леонтьев, 1999: 5). «Функционально грамотным, - от- 
мечают О.П. Чигишева, Е.М. Солтовец, А.В.Бондаренко, - считается тот, кто может участвовать во всех видах деятельности, в которых грамотность необходима для эффективного функционирования его группы, и которые дают ему также возможность продолжать пользоваться чтением, письмом и счетом для своего собственного развития и для развития общества» (Чигишева, 2017: 127).

Э.Г. Азимов и А.Н. Щукин дают следующее определение: функциональная грамотность - это «способность человека вступать в отношения с внешней средой и максимально быстро адаптироваться и функционировать. В отличие от элементарной грамотности как способности личности читать, понимать, составлять короткие тексты и осуществлять простейшие арифметические действия, функциональная грамотность есть уровень знаний, умений и навыков, обеспечивающий нормальное функционирование личности в социальных отношениях, который считается минимально необходимым для осуществления жизнедеятельности личности в конкретной культурной среде» (Азимов, 2009: 342).

«Функциональная грамотность сегодня - это базовое образование личности, поясняет Н.Ф. Виноградова. - Ребенок должен обладать готовностью успешно взаимодействовать в изменяющемся окружающим мире, решать различные (в том числе, нестандартные) учебные и жизненные задачи, строить социальные отношения, давать оценку своей деятельности, стремиться к дальнейшему образованию...» (Виноградова, 2018:16).

В.3. Юсупов и С.В. Капин связывают повышение роли функциональной грамотности педагогов с тем, что «одной из наиболее значимых новаций в новых федеральных государственных образовательных стандартах высшего образования (ФГОС ВО $3++)$ является включение в состав требований к освоению образовательных программ универсальных компетенций, единых по уровням образования для всех направлений и специальностей». Придание формированию компетенций свойств универсальности, исследователи обозначают как «процесс универсализации компетенций» (Юсупов, 2019: 346). Одним из направлений этого процесса является развитие системного критического мышления будущих педагогов, нацеленное на формирование таких важных компонентов функциональной грамотности как способность осуществлять поиск, критический анализ и синтез информации, применять системный подход для решения поставленных задач, вырабатывать стратегию действий.

С позиции культурных констант функциональная грамотность выступает как способ социальной ориентации личности, интегрирующий связь образования (прежде всего - общего) с многообразной человеческой деятельностью. Эта особенность функциональной грамотности проявляется в ее назначении решать жизненные задачи в различных сферах деятельности на основе прикладных знаний, необходимых всем в быстроменяющемся обществе. В этом контексте она превращается из условия в фактор, влияющий на участие людей в социальной, культурной, политической и экономической деятельности, в образовании на протяжении всей жизни. Исходя из этого функциональная грамотность в ее глобальном измерении - индикатор об- 
щественного благополучия, определенных социокультурных достижений общества. Функциональная грамотность это не только индикатор благополучия в обществе, но и эффективный показатель качества образования.

В исследованиях PISA по определению функциональной грамотности в самом вопросе дается пояснение этого понятия: «Обладают ли учащиеся 15-летнего возраста, получившие обязательное общее образование, знаниями и умениями, необходимыми им для полноценного функционирования в современном обществе, т.е. для решения широкого диапазона задач в различных сферах человеческой деятельности, общения и социальных отношений?» (PISA 2018 Assessment and Analytical Framework, 2019).

На основе приведенных определений рассматриваемого понятия, мы будем понимать под функциональной грамотностью способность школьников к овладению такими знаниями, которые позволят ему ориентироваться в сложных современных ситуациях, и умело оценивать их, выстраивать социальные отношения, владеть информационными технологиями, рефлексивными умениями, стремиться к образованию в течение всей жизни.

Российские и зарубежные ученые в последнее десятилетие занимались проблематикой формирования функциональной грамотности у школьников. Как часть культуры информационного общества функциональную грамотность рассматривали В.В. Гаврилюк, О.Е. Лебедев, Г.Г. Сорокин, Ш.Ф. Фарахутдинов и др.

Теоретическая интерпретация исследуемого понятия позволила выделить следующие компоненты функциональной грамотности:

- интегративный (читательская, коммуникативная, информационная, социальная грамотность);

- предметный (языковая, литературная, математическая, естественнонаучная, общекультурная, финансовая, правовая, здорового образа жизни).

Таким образом, индикаторами функциональной грамотности будут являться:

общая грамотность (включающая умение школьников написать сочинение, эссе, заполнить бланки различного содержания, уметь считать без калькулятора, отвечать на вопросы без затруднений);

компьютерная грамотность (умение искать информацию в интернете, справочной литературе, перерабатывать и систематизировать полученную информацию, работать с электронными таблицами, использовать графические редакторы, пользоваться электронной почтой и другими электронными сервисами и мессенджерами);

информационная грамотность (умение отбирать информацию из справочной литературы, читать чертежи, схемы, анализировать числовую информацию, использовать материалы СМИ);

коммуникативная грамотность (умение организовывать и работать в группе, владеть грамотной устной и письменной речью, быстро приспосабливаться к изменившимся условиям), правовая грамотность (уметь отстаивать свои права, объяснять различия и функции государственной власти, законодательства РФ и др.); 
Научные труды Московского гуманитарного университета

2020 № 4

финансовая грамотность (умение планировать денежные расходы, использовать знания и навыки для принятия правильных решений, связанных с деньгами и их тратами);

бытовая грамотность (умение выбирать продукты и товары, умение ориентироваться в незнакомом городе, используя карту-схему, мобильные навигаторы, умение пользоваться различными бытовыми приборами, действовать в чрезвычайных ситуациях и оказывать первую медицинскую помощь).

Необходимо понимать, что один, отдельно взятый педагог на «своём предмете» не сможет осуществить процесс формирования функциональной грамотности в полном объёме, этого результата можно добиться лишь коллективом педагогов, работая в двух направления (учебный процесс и внеурочная деятельность) по формированию функциональной грамотности. Учитель должен ориентироваться на изменения в содержании учебного предмета с учетом на самопознание, разработку и внедрение практико-ориентированных модулей с использованием ученического исследования, реализацию комплексного подхода к исследовательской деятельности в образовательном процессе, организацию сотрудничества на основе субъектных отношений всех участников образовательных отношений. Тщательно продуманные уроки, выбор образовательной технологии, самостоятельная работа учащихся на уроке, все это в комплексе дает возможность формировать функциональную грамотность.

Очевидно и то, что ученик не может усваивать материал только через личное исследование - это не только затратно по времени, но и полученный результат может быть не высок. Поэтому уместно использовать на уроках элементы исследовательского метода обучения.

Базовым умением в формировании функциональной грамотности является способность понимать текст, понять авторскую позицию, логическую структуру текста, выделить главную мысль. При отборе заданий учитель использует разные типы текстов, направленные на анализ, сопоставление, сравнение, составление схем и таблиц, работу со справочной литературой. Для развития умения видеть проблему можно использовать специальные задания. Например, по истории Древнего мира $(5$ класс): «Составьте рассказ от имени торговца в порту Пирей» или «...от имени сборщика налогов в Египте». Для того чтобы видеть проблему, учащийся должен научиться наблюдать. Чаще всего метод наблюдения используется в биологии (проращивание семян, выгонка луковичных растений), географии (ведение календаря погоды), но также можно использовать данный метод в предметах гуманитарного цикла при работе с иллюстрациями.

Умение выдвигать гипотезы и строить предположения является одним из ключевых моментов в исследовательской деятельности. Использование в учебном процессе провокационных вопросов помогает учащимся при выдвижении гипотезы использовать слова-клише, такие как: допустим, предположим, может быть и т.д.

Коммуникативные умения формируются в парной и групповой работе. Способность учителя организовать на уроке дискуссию позволяет формировать не толь- 
ко навык публичного выступления, но и умение рефлексировать. В дискуссии учащиеся не только выступают с собственной точкой зрения, но и принимают позицию оппонентов, которые могут подвергнуть сомнению и критике сказанное.

Навык экспериментирования - один из главных в исследовании, поскольку любой эксперимент предполагает выполнение практических действий, проверку данных и сравнение. В отличие от мыслительных экспериментов, реальные эксперименты более эмоционально насыщены по восприятию. Например, использование катушки Тесла на уроках физики, принцип работы которой заключается в высоковольтном резонансном действии, работающем на высокой частоте. Опыты по определению свойств и поверхностное натяжение воды, смешивание красок для получения нового цвета и оттенка. В результате деятельности учащиеся выдвигают гипотезы, которые потом практическим путем проверяют.

Обязательным условием формирования функциональной грамотности является наличие творческого домашнего задания. Это могут быть синквейны, эссе, составление памяток, написания резюме, работа с таблицами и т.д. в зависимости от уровня подготовки учащихся.

В процессе решения задач по формированию функциональной грамотности посредством исследовательской деятельности, педагогу необходимо уйти от позиции носителя информации к позиции консультанта (тьютора).

Внеурочная деятельность является логическим продолжением учебного процесса, в нее входит работа кружков, элективных, факультативных занятий, метапредметных курсов. В рамках внеурочной деятельности предполагается поэтапное развитие различных умений, составляющих основу функциональной грамотности. Занятия внеурочной деятельности проходят в менее регламентированном режиме, с применением знаний и умений, ранее полученных на уроках.

Внеурочная деятельность носит продуктивный характер и включает в себя следующие виды деятельность: экскурсии, экспедиции, конкурсы, праздники, конференции, олимпиады, концерты, марафоны, выставки, дискуссии, спектакли, круглые столы, мастер-классы, ролевые игры, лаборатории, мастерские. В результате внеурочной деятельности у учащегося должно формироваться умение учится самостоятельно, добывать и систематизировать новые знания.

Формирование функциональной грамотности через исследовательскую деятельность - процесс длительный и многосторонний. Однако, положительных результатов можно добиться при соблюдении принципов непрерывности образования, развития индивидуальности каждого ребенка, системности организации образовательного процесса, раскрытия и поддержки талантливых детей. Тогда процесс формирования функциональной грамотности через исследовательскую деятельность будет полным и целостным.

Федеральные государственные образовательные стандарты предполагают овладение учащимися исследовательскими умениями и выполнение учащимся проектно-исследовательской работы по одному из учебных предметов или любой выбран- 
ной области знаний. Следовательно, проект или исследование будут выполнять все учащиеся.

Проведённое нами исследование позволило выделить критерии и уровни сформированности функциональной грамотности (таблица 1).

Таблица 1

\section{Уровни сформированности функциональной грамотности средствами исследовательской деятельности}

\begin{tabular}{|c|c|c|c|}
\hline \multirow{2}{*}{ Критерии } & \multicolumn{3}{|c|}{ Уровни сформированности } \\
\hline & Оптимальный & Допустимый & Критический \\
\hline $\begin{array}{l}\text { Мотивационный } \\
\text { критерий }\end{array}$ & $\begin{array}{l}\text { Положительная мо- } \\
\text { тивация, направлен- } \\
\text { ность на активное } \\
\text { включение в образо- } \\
\text { вательное простран- } \\
\text { ство школы, дости- } \\
\text { жение цели; осоз- } \\
\text { нание собственных } \\
\text { образовательных по- } \\
\text { требностей }\end{array}$ & $\begin{array}{l}\text { Присутствует включение } \\
\text { в образовательный про- } \\
\text { цесс школы, наблюдает- } \\
\text { ся мотивация к учебным } \\
\text { предметам; происхо- } \\
\text { дит осознание ценност- } \\
\text { но-смысловых результа- } \\
\text { тов деятельности }\end{array}$ & $\begin{array}{l}\text { Отрицательная моти- } \\
\text { вация, низкая мотива- } \\
\text { ция, слабая настойчи- } \\
\text { вость в достижении } \\
\text { цели }\end{array}$ \\
\hline $\begin{array}{l}\text { Когнитивный } \\
\text { критерий }\end{array}$ & $\begin{array}{l}\text { Качественное владе- } \\
\text { ние знаниями в изме- } \\
\text { няющихся условиях. } \\
\text { Практическое владе- } \\
\text { ние знаниями в не- } \\
\text { стандартных ситуа- } \\
\text { циях; при изменении } \\
\text { формулировки зада- } \\
\text { ния, при выполнении } \\
\text { не типовых заданий, } \\
\text { при переносе знаний } \\
\text { на новый материал }\end{array}$ & $\begin{array}{l}\text { Частичное владение зна- } \\
\text { ниями в нестандартных } \\
\text { ситуациях; при измене- } \\
\text { нии формулировки зада- } \\
\text { ния, при выполнении не } \\
\text { типовых заданий, при пе- } \\
\text { реносе знаний на новый } \\
\text { материал }\end{array}$ & $\begin{array}{l}\text { Низкое владение зна- } \\
\text { ниями в нестандарт- } \\
\text { ных ситуациях; ис- } \\
\text { пытывает трудности } \\
\text { при изменении фор- } \\
\text { мулировки задания; } \\
\text { при выполнении не } \\
\text { типовых заданий, при } \\
\text { переносе знаний на } \\
\text { новый материал }\end{array}$ \\
\hline $\begin{array}{l}\text { Деятельностный } \\
\text { критерий }\end{array}$ & $\begin{array}{l}\text { Умение успешно осу- } \\
\text { ществлять действия } \\
\text { самостоятельной и } \\
\text { научно - исследова- } \\
\text { тельской работы на } \\
\text { основе имеющихся } \\
\text { знаний; выбор спо- } \\
\text { соба планирования; } \\
\text { способность анали- } \\
\text { зировать, интерпре- } \\
\text { тировать, представ- } \\
\text { лять информацию в } \\
\text { новом виде }\end{array}$ & $\begin{array}{l}\text { Наличие умений осу- } \\
\text { ществлять действия само- } \\
\text { стоятельной и научно-ис- } \\
\text { следовательской работы } \\
\text { на базе имеющихся зна- } \\
\text { ний, частичное владение } \\
\text { способами планирования } \\
\text { и деятельности по реше- } \\
\text { нию поставленных задач; } \\
\text { испытывает затруднения } \\
\text { при аналитической дея- } \\
\text { тельности, переработке } \\
\text { информации и представ- } \\
\text { лении ее в новом виде }\end{array}$ & $\begin{array}{l}\text { Наличие умений для } \\
\text { осуществления дей- } \\
\text { ствий самостоятель- } \\
\text { ной работы на базе } \\
\text { имеющихся знаний; } \\
\text { отсутствие умений } \\
\text { выбора способов пла- } \\
\text { нирования, интерпре- } \\
\text { тации информации }\end{array}$ \\
\hline
\end{tabular}


Научные труды Московского гуманитарного университета

2020 № 4

Продолжение таб. 1

\begin{tabular}{|c|c|c|c|}
\hline \multirow{2}{*}{ Критерии } & \multicolumn{3}{|c|}{ Уровни сформированности } \\
\hline & Оптимальный & Допустимый & Критический \\
\hline $\begin{array}{l}\text { Информационный } \\
\text { критерий }\end{array}$ & $\begin{array}{l}\text { Умение ставить и } \\
\text { решать информаци- } \\
\text { онную задачу с по- } \\
\text { мощью справочных } \\
\text { источников, словарей, } \\
\text { Интернет; свободное } \\
\text { владение речью }\end{array}$ & $\begin{array}{l}\text { Умение решать информа- } \\
\text { ционную задачу с помо- } \\
\text { щью справочных источ- } \\
\text { ников, словарей, Интер- } \\
\text { нет; при свободном вла- } \\
\text { дение речью испытывает } \\
\text { затруднения }\end{array}$ & $\begin{array}{l}\text { Умение решать ин- } \\
\text { формационную зада- } \\
\text { чу с помощью Интер- } \\
\text { нет; владение речью } \\
\text { затруднено }\end{array}$ \\
\hline $\begin{array}{l}\text { Рефлексивный } \\
\text { критерий }\end{array}$ & $\begin{array}{l}\text { Адекватная самоо- } \\
\text { ценка - умение по- } \\
\text { ставить задачи на } \\
\text { саморазвитие и само- } \\
\text { совершенствование; } \\
\text { критическое рассмо- } \\
\text { трение своей дея- } \\
\text { тельности; выработка } \\
\text { собственной позиции }\end{array}$ & $\begin{array}{l}\text { Способность составлять } \\
\text { перспективные планы в } \\
\text { соответствии со своими } \\
\text { возможностями и целя- } \\
\text { ми; частичное критиче- } \\
\text { ское оценивание своей } \\
\text { деятельности; отсутству- } \\
\text { ет собственная позиция }\end{array}$ & $\begin{array}{l}\text { Испытывает труд- } \\
\text { ности способность } \\
\text { составлять перспек- } \\
\text { тивные планы в со- } \\
\text { ответствии со свои- } \\
\text { ми возможностями и } \\
\text { целями, отсутствует } \\
\text { умение критически } \\
\text { оценивать свою дея- } \\
\text { тельность, слабое вла- } \\
\text { дение умениями рабо- } \\
\text { тать с информацией }\end{array}$ \\
\hline
\end{tabular}

Данные, приведенные в таблице, дают нам возможность понять, насколько хорошо сформирована функциональная грамотность учащихся.

Отдавая предпочтение исследовательской деятельности, введенной как в урочную, так и во внеурочную деятельность, можно отметить ее эффективность в формировании функциональной грамотности обучающихся. Именно исследовательская деятельность позволяет включать учащихся в поиск решений проблемных ситуаций современного мира, учит находить информацию, хранить и обрабатывать ее, устанавливать закономерные связи, вести самостоятельную работу, работать в коллективе, распределять время работы, оценивать результаты своего труда и давать оценку результату труда других.

Использование исследовательской деятельности не только оживляет учебный процесс, но и обогащает знаниями, полученными в результате самостоятельной поисковой деятельности, которые становятся долговременными и прочными. Универсальность исследовательской деятельности позволяет использовать ее во всех предметах учебного плана.

\section{СПИСОК ЛИТЕРАТУРЫ}

Азимов, Э.Г., Щукин, А.Н. (2009) Новый словарь методических терминов и понятий (Теория и практика обучения языкам). М.: Икар, 448 с.

Леонтьев, А.А. (1999) От психологии чтения к психологии обучению чтению // Начальная школа: плюс-минус. - № 10. - 1999. С.43-47. 
PISA (2019) Assessment and Analytical Framework. Paris: OECDPublishing, 2019 [Электронный ресурc] URL: https://www.oecd.org/education/pisa-2018-assessmentand-analytical-framework-b25efab8-en.htm (Дата обращения: 05.06.2020).

Чигишева О.П., Солтовец Е.М., Бондаренко А.В. (2017) Интерпретационное своеобразие концепта «функциональная грамотность» в российской и европейской теории образования // Интернет-журнал «Мир науки». Том 5. №4. [Электронный реcypc] URL: http://mir-nauki.com/PDF/45PDMN417.pdf (Дата обращения 13.07.2020).

Юсупов, В.3., Капин С.В. (2019) Универсализация проектной компетенции будущего педагога на основе междисциплинарного подхода // II Моисеевские чтения: Культура как фактор национальной безопасности: доклады и материалы Общероссийской (национальной) научной конференции. Москва, 26 июня 2019 г. / под ред. А.В. Костиной, В.А. Лукова. - М.: МосГУ, 2019. С. 346-355.

Корнилова Татьяна Владимировна - аспирант кафедры педагогики и психологии высшей школы Московского гуманитарного университета. Научный руководитель - д.п.н., проф. Юсупов В.З. Адрес: 111395, Россия, г. Москва, ул. Юности, д. 5. Тел.: +7 (499) 374-74-59. Эл. адрес: tanya_kornilova_@mail.ru.

Kornilova Tatyana Vladimirovna - is a post-graduate student of the Department of pedagogy and psychology of the higher school, Moscow University for the Humanities. Scientific supervisor-doctor of science, prof. Yusupov V.Z. Postal address: 5 Yunosti Str., 111395, Moscow, Russian Federation. Tel.: +7 (499) 374-74-59 E-mail: tanya_kornilova_@mail.ru.

\section{Для цитирования:}

Корнилова Т.В. Исследовательская деятельность школьников как способ формирования функциональной грамотности // Научные труды Московского гуманитарного университета. 2020. №4. C. 56-63. DOI: https://www.doi.org/10.17805/trudy.2020.4.8 